\title{
La antigua Plaza de Armas y el Kiosco Morisco de San Cristóbal de Las Casas
}

\author{
Víctor Manuel Esponda Jimeno
}

\section{Introducción}

L a plaza principal de la antigua Ciudad Real ha sido el espacio público de mayor actividad social; en ella ocurrieron y ocurren variados sucesos y eventos de distinto carácter y orden. La Plaza de Armas, como se le conoció a este lugar, es por definición el corazón de la ciudad, alrededor de ella se establecieron los principales edificios, tanto públicos como privados: la Iglesia Catedral, Las Casas Consistoriales, los comercios y las casas de los principales habitantes de la ciudad. En suma, a ella concurren todas las arterias que se trazaron en la primitiva Ciudad Real. El nombre de "centro" le viene muy bien por ser el punto principal de la vida política, económica, cívica, cultural, etcétera.

Las plazas de armas son un legado castellano y su presencia significó el establecimiento de un nuevo orden político social, espacio de confluencia múltiple. La plaza central de San Cristóbal ha tenido una paulatina transformación; cuando era Ciudad Real su uso fue múltiplee intenso, allí se mercaba, estaban los comercios

Víctor Manuel Esponda Jimeno, Doctor en Antropología por la ENAH. Cuerpo Académico: Patrimonio Sociocultural del Centro de Estudios Superiores de México y Centro América de la Universidad de Ciencias y Artes de Chiapas. establecidos y los móviles, los primeros representados por los vecinos de la ciudad y los segundos por los hortelanos y campiranos que concurrían trayendo sus mercaderías desde diferentes parajes. En dicha plaza se llevaban a cabo homenajes, reuniones, ceremonias, paseos, pregones, remates y avisos diversos. En ella estaba la fuente grande que además de ornato surtía de agua al centro de la población. En este sitio se ejecutaron a los delincuentes, se celebraron diversos festejos, se concentró a multitudes para distintos sucesos, ya bélicos como lúdicos, etcétera, etcétera. Muy extenso espacio ocuparía relacionar los usos y sucesos que tuvieron lugar en la plaza central de San Cristóbal y en tal virtud es menester delimitar el alcance de esta nota, que sólo aspira presentar, grosso modo, una semblanza del espacio en que se edificó el kiosco que ahora tiene una antigüedad de más de un siglo - véase anexo fotográfico del siglo XX.

La primera noticia gráfica que se tiene de esta plaza data de finales del siglo XVIII, se trata de un plano rústico con escala de 100 varas castellanas que ilustra la distribución que en ese entonces tenía el cuadrilongo principal. Al centro se ilustra una pila y los portalillos de los caxones. Así parece haber sido diseñada dicha plaza -finales del siglo XVI y principios del XVII— de la joven Ciudad Real, la que persistió en ese estado hasta la 
segunda mitad del XIX (Figura l). En ese plano se ubican las Casas Consistoriales en el ángulo norponiente de la plaza, a un lado de la casa de don Juan de Velasco y Martínez.

En 7 de marzo de 1863 se reporta el incendio perpetrado por los facciosos Juan Ortega y Víctor Chanona que acabó con la Casa de Gobierno y con su valioso contenido. ${ }^{1}$ Es claro que las Casas Consistoriales a que se refiere el mencionado plano ya no estaban en esta época en el lugar que se les ubica. Una litografía del famoso grabador ${ }^{2}$ Hesequio Iriarte (Figura 2) que aparece en la novela de Flavio Paniagua, Una rosa y dos espinas (1874), recrea este trágico suceso - aunque erróneamente anota que fue en agosto de 1863indicando que tales casas estaban en el lado Este, justo en la esquina nororiente que el referido plano indica que eran las moradas de doña Josefa Antonia Obeso Coello, la del Teniente Letrado y la de doña Manuela del Agua y Culebro. En la litografía se observa que en 1863 el espacio que ocupaban las casas consistoriales del siglo XVIII está arruinado y abandonado. Algo ocurrió después de 1825, y quizá alguno de los tantos traslados provisionales de los poderes públicos que se hizo debido a la inestabilidad política y a los conflictos belicosos, dio lugar a que las viejas Casas Consistoriales se hayan abandonado o sido destinadas a otro fin.

La Reforma cambió la estructura y fisiografía de la ciudad, sobre todo en la parte sur, mas la plaza principal mantuvo su fisiografía, aunque andando el tiempo se hicieron ligeras modificaciones.

La plaza ha tenido distintos nombres, sobre todo a partir de la segunda mitad del siglo XIX, un viejo dibujo del artista sancristobalense Pedro Martínez nos recrea la añeja imagen de este espacio en el año 1869, cuando fue ejecutado públicamente Ignacio Fernández de Galindo, sedicioso mercenario que involucró a los indios chamulas en una trágica lucha (Figura 3). En ella se consiga una vistosa fuente en forma de corona rematada en sus extremos por cuatro obeliscos y alrededor de ella los caxones (cf. la obra de Iriarte que ofrece otra perspectiva inversa), las Casas Consistoriales sitas al norponiente se observan destruidas. Debe notarse que por ser la capital había más de un edificio público: casa municipal, casa de poderes, asamblea departamental, tribunal, cárcel, cuartel, congreso, colegios, seminario, palacio episcopal, etcétera, que estaban cercanos al centro, la mayoría hacia el sur en los linderos del convento de la Encarnación e inmediatos al convento de San Francisco.

Al parecer las modificaciones que ha sufrido la referida plaza tuvieron lugar después de 1870, pero conservando los locales mercantiles - caxones-. En marzo de 1887 se reporta que dicha plaza se encontraba en un estado de descuido y de inmediato se nombró a una comisión para encargarse de su arreglo y ornato. La iniciativa de rehabilitar el parque fue del oaxaqueño, don José Jimeno de Jiménez que a la sazón ocupaba la presidencia municipal "por Ministerio de la Ley". Las obras se iniciaron con entusiasmo y empeño, al grado de que en mayo se tenía la obra casi concluida y a la vez se le había signado el nombre de "Jardín de la Reforma"; un concejal, C. Alfredo Aguilar, miembro a la vez de la junta mencionada, excediendo sus facultades pretendió inaugurarla, sin previo aviso ni autorización del ayuntamiento, el domingo 5 de mayo, ${ }^{4}$ por esta acción fue sancionado y las obras de remozamiento y ornato del jardín continuaron, habiéndose inaugurado formalmente ${ }^{5}$ el 1 de diciembre del citado año.

A poco tiempo de su inauguración, en la noche del 16 de enero de 1888 ocurrió un incendio que destruyó varios establecimientos mercantiles - caxones- que estaban alrededor del parque, sobre todo los ubicados al oriente, que eran negociaciones de Wenceslao Paniagua, José Manuel Robles, Vicente Farrera, y otros. Estos pretendieron reconstruirlos pero el ayuntamiento no les concedió autorización. Se demolieron los caxones arruinados que quedaban y se amplió la plaza. El jardín se arregló un poco y conservó su nombre hasta 1894, al siguiente año se emprendió otra modificación. Es de advertir que durante muchos años, incluso en la 
primera mitad del XX, ${ }^{6}$ los contornos de la plaza servían de mercado, uso que objetaban no pocos vecinos por considerarlo inadecuado. Un grupo de comerciantes, Teofilo Orantes, Filemón Marcelín, Antonio Carboney y Carlos Gris solicitaron en 1891 licencia al ayuntamiento para formar una sociedad y construir ${ }^{7}$ un mercado en los terrenos del ex convento de San Francisco, no se concretó esa idea y el mercado siguió montándose en las arterias de la plaza.

El incendio de los caxones marcó la pauta para la nueva traza del parque central y fue el mayor Vicente Espinosa, a la sazón visitador general de jefaturas políticas y a la postre jefe político del Departamento del Centro, quien en 1895 tomó la iniciativa de hacerlo. Los trabajos de traza y construcción se iniciaron ese año y con gran empeño y constancia se hizo la distribución del parque, situando jardineras, andadores, glorietas, fuentes, obeliscos; toda la plataforma fue guarnecida de calicanto y cubierta su superficie con amplias lajas, concluyéndose en 1897. El trabajo fue intenso y, sin duda, inspirado por los modelos que en boga puso el porfirismo: amplios jardines o alamedas a guisa de paseos.

\section{El documento}

Aunque breve, su contenido es sustancioso y expresa de manera diáfana cómo la influencia del centro era acatada sin miramientos, en este caso, contar con una plaza de armas al estilo dominante y eliminar la vetusta imagen castellana de las viejas plazas; esto es, modernizar. El documento sólo refiere la edificación del kiosco que en este año cumplió 113 años de vida, habiendo sufrido algunas transformaciones que fueron motivo de desacuerdo y disgustos; algunos opinaban que la plaza debería ser abierta y despejada, otros que debería estar arbolada. El parque central se llamó Jardín de la Reforma y luego Vicente Espinosa; en pleno siglo se le se denominó al conjunto, no al parque, Plaza 31 de Marzo, y así persiste hasta nuestros días. El documento que a continuación se presenta es un acta de la sesión extraordinaria que se halla en el Libro de actas de 1897, a foxa 9 r/v. Archivo Histórico Municipal de San Cristóbal de Las Casas.

Sesión extraordinaria del día $1^{\circ}$. de febrero de 1897

Presidencia del ciudadano R. A. Blanco

Asistieron los concejales Tovilla, Cancino, Gutiérrez (Agapito), Flores, Correa, Bermúdez, Castillo, Díaz, Rodas, Bonifaz, Martínez, Román y síndicos primero y segundo.

La sesión se abrió con la lectura del acta anterior que fue aprobada sin discusión.

El presidente manifestó: que próximo como está el aniversario de nuestra Carta Fundamental, el 5 de Febrero, día que se inaugurará el kiosco del parque principal de esta ciudad, había tenido a bien citar a sesión extraordinaria a todos los señores concejales para [v.9] acordar la manera mejor para celebrar dicha fiesta y proponer un premio de honor al patriota y desinteresado fundador de tan importante obra, Señor Jefe Político, Mayor Vicente Espinosa, entendidos los señores que componen el $\mathrm{H}$. cuerpo unánimes acordaron:

Que para el día citado se reunirán todos en el local ya destinado para el efecto y reunidos pasarían al kiosco a recibir del Señor Jefe Político la obra indicada, en seguida tomaría la palabra el síndico $2^{\circ}$. ciudadano Abel Lazos para darle las más debidas gracias al Señor Jefe Político, y al mismo tiempo el Señor Presidente del cuerpo colocará en el pecho del Señor Jefe Político un escudo de oro con el nombre del señor Espinosa que le dedica el $\mathrm{H}$. Ayuntamiento de 1897; e igualmente se hizo también un Cartón dedicado al señor Jefe Político en agradecimiento de sus afanes, acordándose fuera firmado por todo el cuerpo municipal para su constancia, mandando hacer dos ejemplares del Cartón, uno para el Señor Jefe Político y otro para que sea colocado en el Salón de Cabildos para su conservación y memoria.

Terminó la sesión.

Ramón A. Blanco [firma]

Regidor $3^{\circ}$. 


\section{Agapito Gutiérrez [firma] \\ Regidor $5^{\circ}$. \\ Romualdo Flores Correa [firma] \\ Regidor $6^{\circ}$. \\ Rómulo Bermúdez [firma]}

\section{Comentario}

A los 113 años de trayectoria al parque y su kiosco morisco, que ha servido a diversos giros, siendo el primero para albergar a los músicos de las bandas municipales, utilizado también para local de cantina en los años veinte, ${ }^{8}$ luego biblioteca, restaurante, librería, café y sobre todo por ser punto de encuentro y escenario de innumerables filarmónicos; un arbitrario edil municipal, en un acto de lambisconería en 2004, "acordó" con su cuerpo de concejales cambiarle el nombre del viejo parque por el de "Dr. Manuel Velasco Suárez", habiendo montado en un recoveco de una de las jardineras la estatua de este preclaro hombre, que en Chiapas llevan su nombre numerosos poblados, calles, escuelas, colonias, etcétera. Los méritos del galeno están bien premiados y reconocidos mundialmente y no hace falta que el parque que por muchos años se conoce por Vicente Espinosa — aunque posteriormente se le llamó a todo el conjunto Plaza 31 de Marzo-, y que fue iniciativa de él y producto de sus constante esfuerzos, se le cambie el nombre. El mayor Espinosa, oriundo de Oaxaca, hombre activo y enérgico, ejecutó variadas obras y acciones materiales en beneficio de la Ciudad. Sus severas acciones lastimaron intereses de algunas personas que gozaban de privilegios y por tal motivo se ganó no pocos rencores; su fotografía que se encontraba en el salón de cabildos después de 1899 fue retirada y desaparecida por su enemigos políticos, no obstante su memoria perdura en el curioso kiosco — que la gente de antaño llamaba "morisco", cuya influencia árabe apenas si se percibe- - Durante el siglo XX la vieja plaza ha cambiado no pocas veces su fisiografía; el vistoso parque que fue, adornado de fuentes, desde hace muchos años carece de ellas, tal parece que los presidentes municipales que han sido de esta ciudad no gustan de las "risueñas" y vistosas "pilas" que eran elemento indispensable de todo parque.

\section{Notas}

${ }^{1}$ Flavio A. Paniagua (Una rosa y dos espinas, 1991, p. 101 [1874, capítulo VII]) describe el panorama desolador de San Cristóbal cuando Ortega y Chanona sitiaron la ciudad; respecto a la casa consistorial, que no indica su ubicación, dice que estaba "situada de norte a sur en la plaza de San Cristóbal, era de dos pisos; en el de arriba estaban colocados los despachos, el ayuntamiento y alcaldes, en los de abajo estaba situado el cuartel y cárcel".

${ }^{2}$ Que por su estilo y técnica parece haber sido tomada de uno de los dibujos del pintor Pedro Martínez.

${ }^{3}$ Sesión ordinaria de 29 de marzo, Libro de Actas del Ayuntamiento de esta Capital de 1887, foja 33v. Archivo Histórico Municipal de San Cristóbal de Las Casas, en adelante AHM.

${ }^{4}$ Un miembro de la comisión referida, C. Mauricio González, hizo notar en sesión extraordinaria de 12 de mayo "Que el Sr. Aguilar, por sí solo y sin darle conocimiento, abrió el Paseo 'Reforma' el domingo pasado intentando su inauguración sin acuerdo de esta respetable corporación, siendo el exponente parte integrante de la comisión de policía i ornato de este paseo; pongo en conocimiento de esta corporación la extralimitación de facultades del regidor Aguilar a fin de que la corporación delibere sobre el particular" (Libro, id, foja 41 r. AHM).

${ }^{5}$ Libro id. Foja 72r. AHM.

${ }^{6}$ En lo que hoy es el parque de Los Arcos, justo atrás del palacio municipal, estuvo el viejo mercado que después se trasladó a San Francisco y luego a la plazuela de la Merced.

${ }^{7}$ Libro de actas de 1891, foja 14r. AHM. 
8 Cuyo propietario, don Aureliano Hernández, anunciaba que era "Especial para familias - Servicio de Cantina de Primer Orden- Helados, Refrescos, Sidras, etcétera" (Boletín de la Cámara de Comercio,
Agricultura e Industria. San Cristóbal Las Casas, marzo 31 de 1928, p. 37). (Boletín de la Cámara de Comercio, Agricultura e Industria. San Cristóbal Las Casas, marzo 31 de 1928, p. 37).

\section{Anexo fotográfico del siglo XX}

Figura 1. Plano del siglo XVIII.

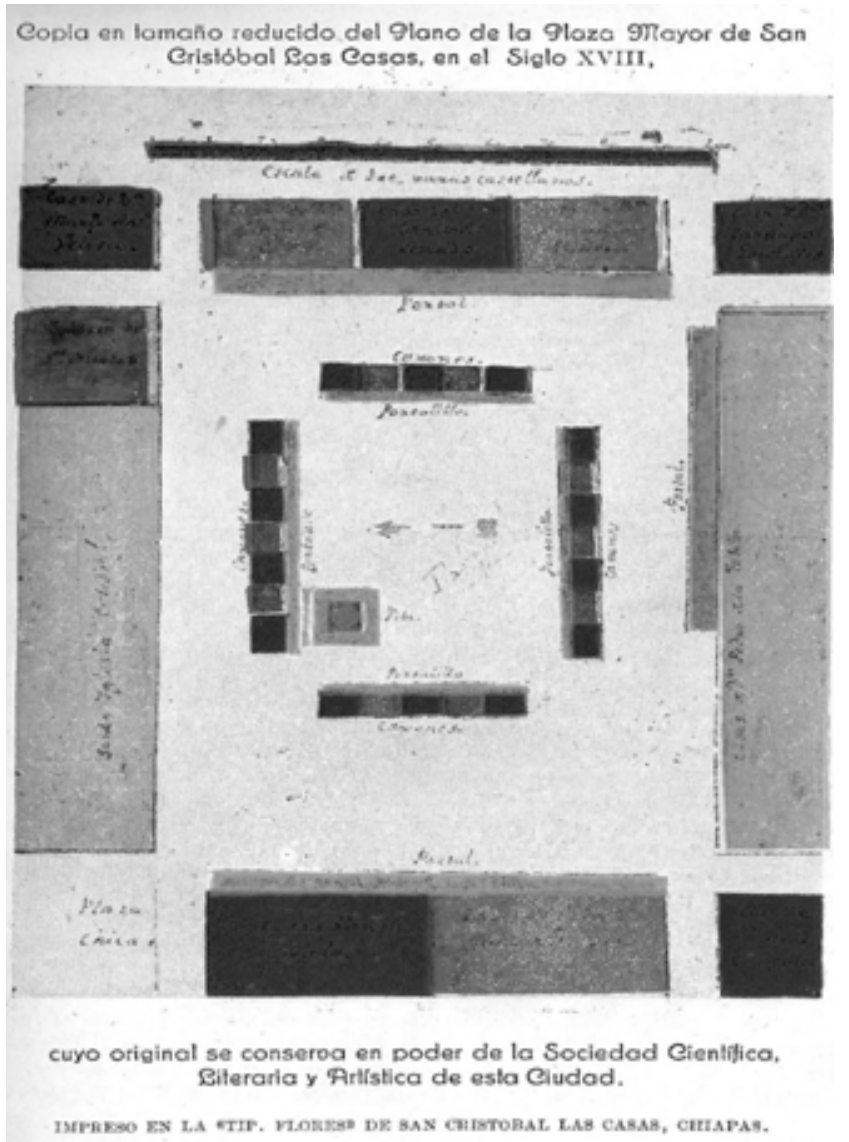

Revista LiminaR. Estudios sociales y humanísticos, año 8, vol. VIII, núm. 2, diciembre de 2010, San Cristóbal de Las Casas, Chiapas, México. ISSN: 1665-8027 
Figura 2. Incendio de la casa de Gobierno. 7 de mayo de 1863. Litografía de Hesequio Iriarte.

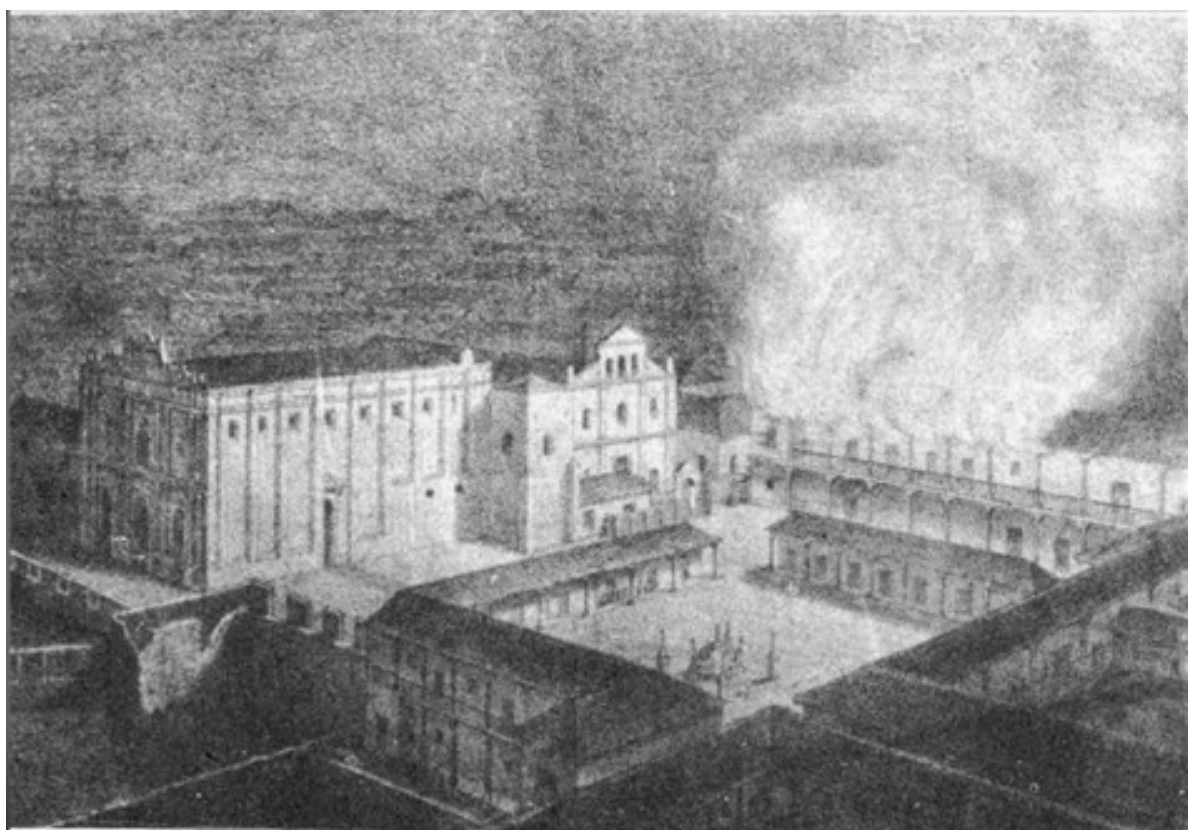

Figura 3. Litografía de J. Pedro Martínez.

Ejecución de Galindo y Trejo en la plaza principal de S.C., el 26 de junio. N. 5.

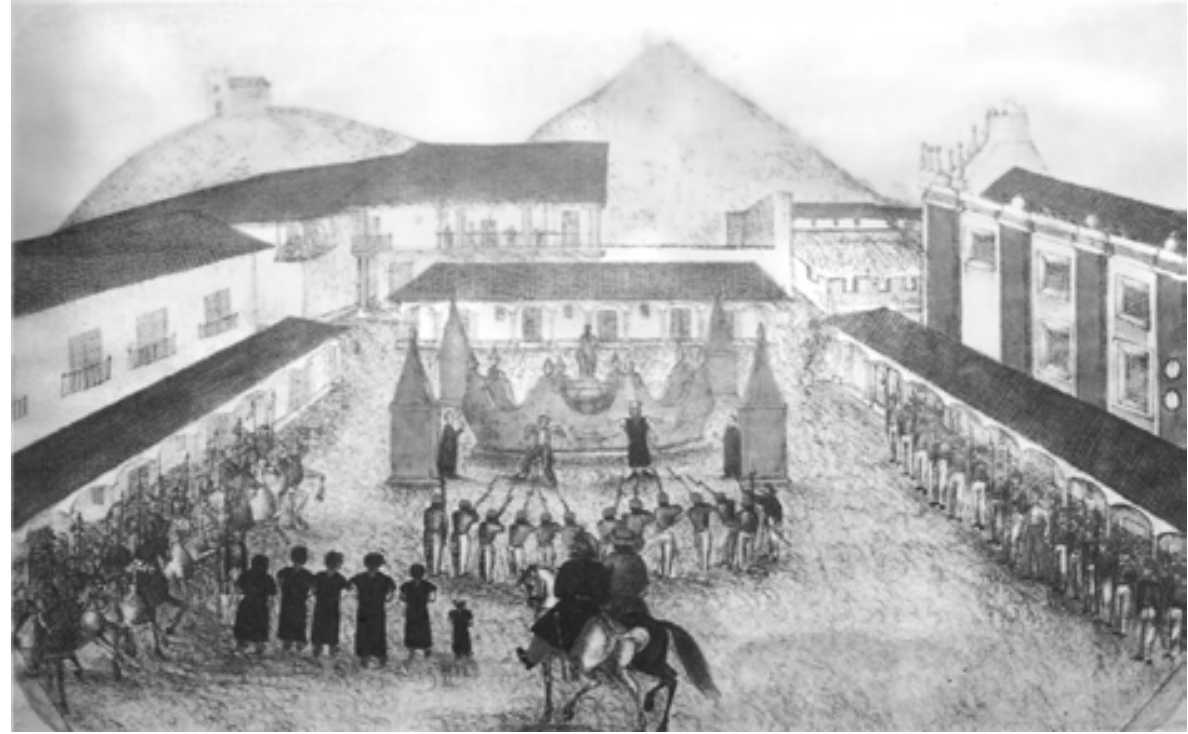




\section{a) Plaza principal, 1896.}

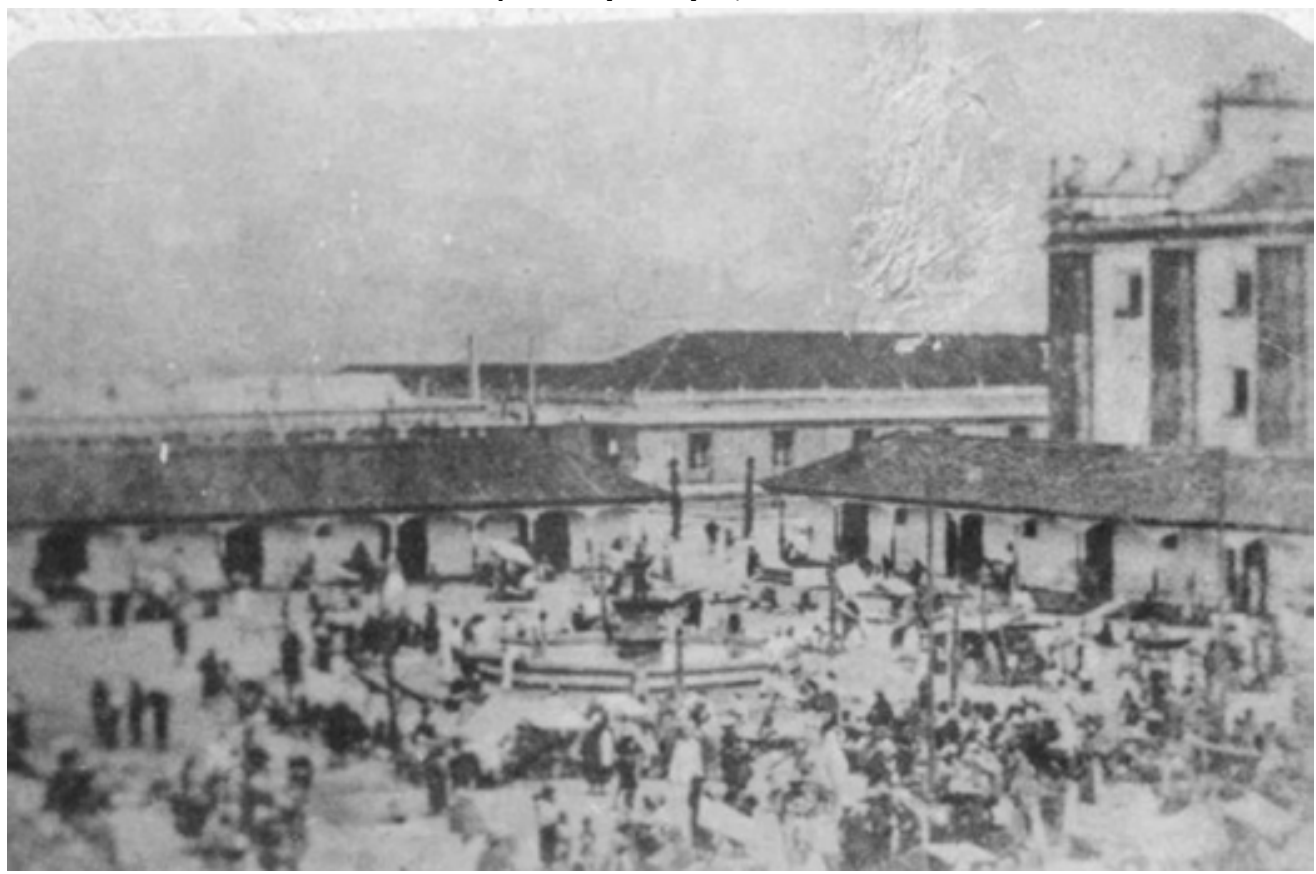

b) Parque , 1930.

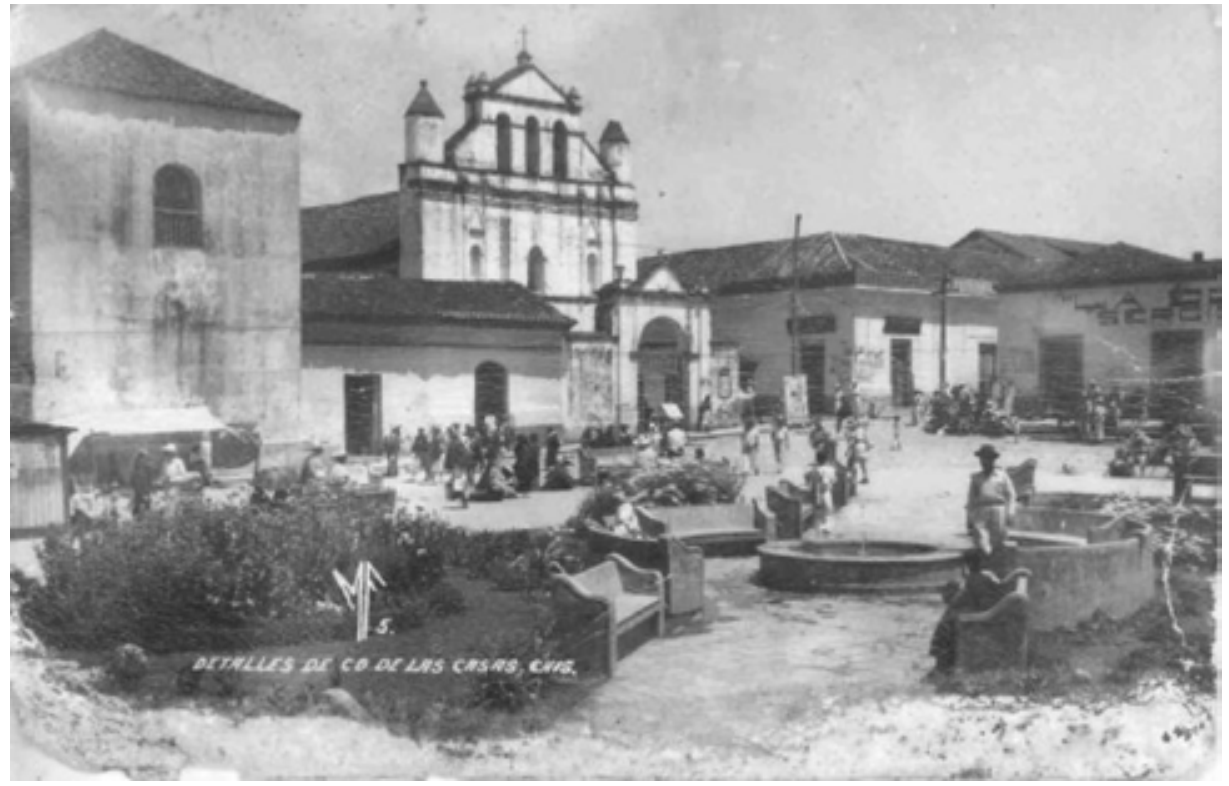

Revista LiminaR. Estudios sociales y humanísticos, año 8, vol. VIII, núm. 2, diciembre de 2010, San Cristóbal de Las Casas, Chiapas, México. ISSN: $1665-8027$ 
c) Kiosco en el parque Vicente Espinosa, San Cristóbal de Las Casas, 1925.

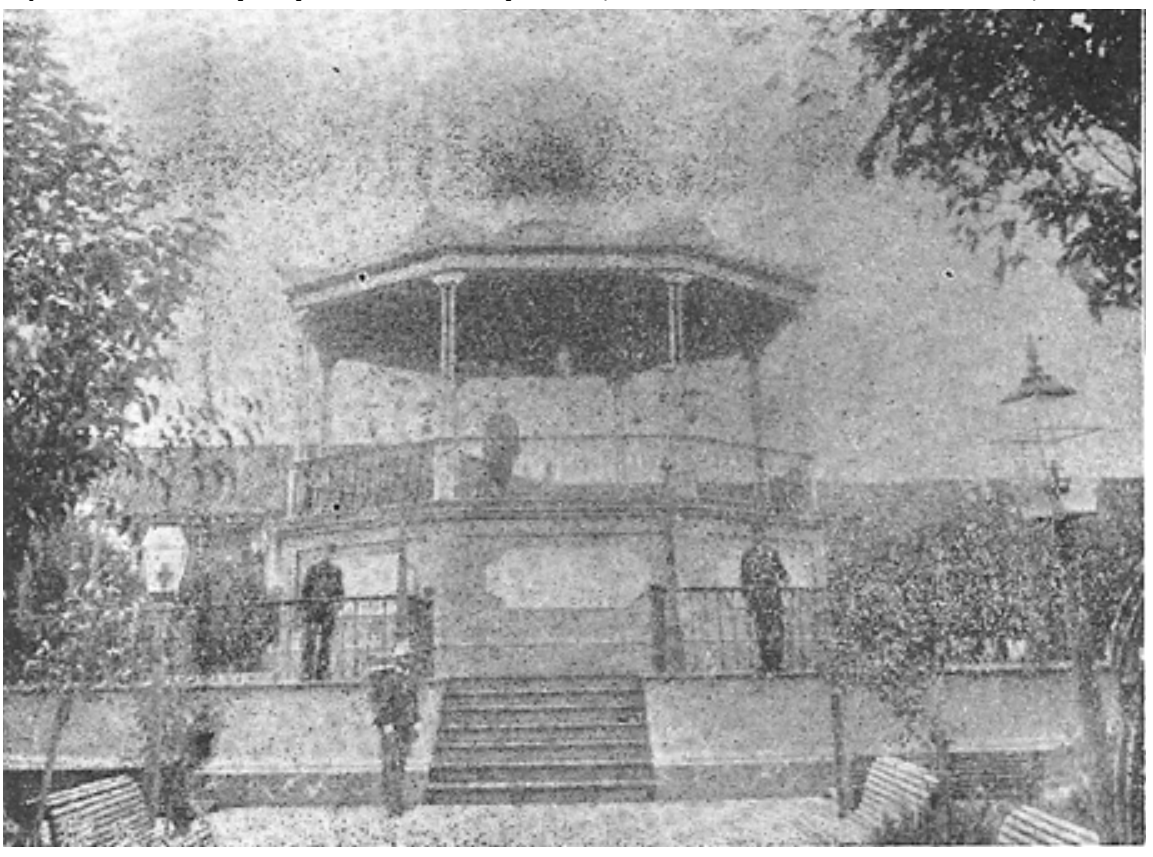

d) Kiosco, 1938.

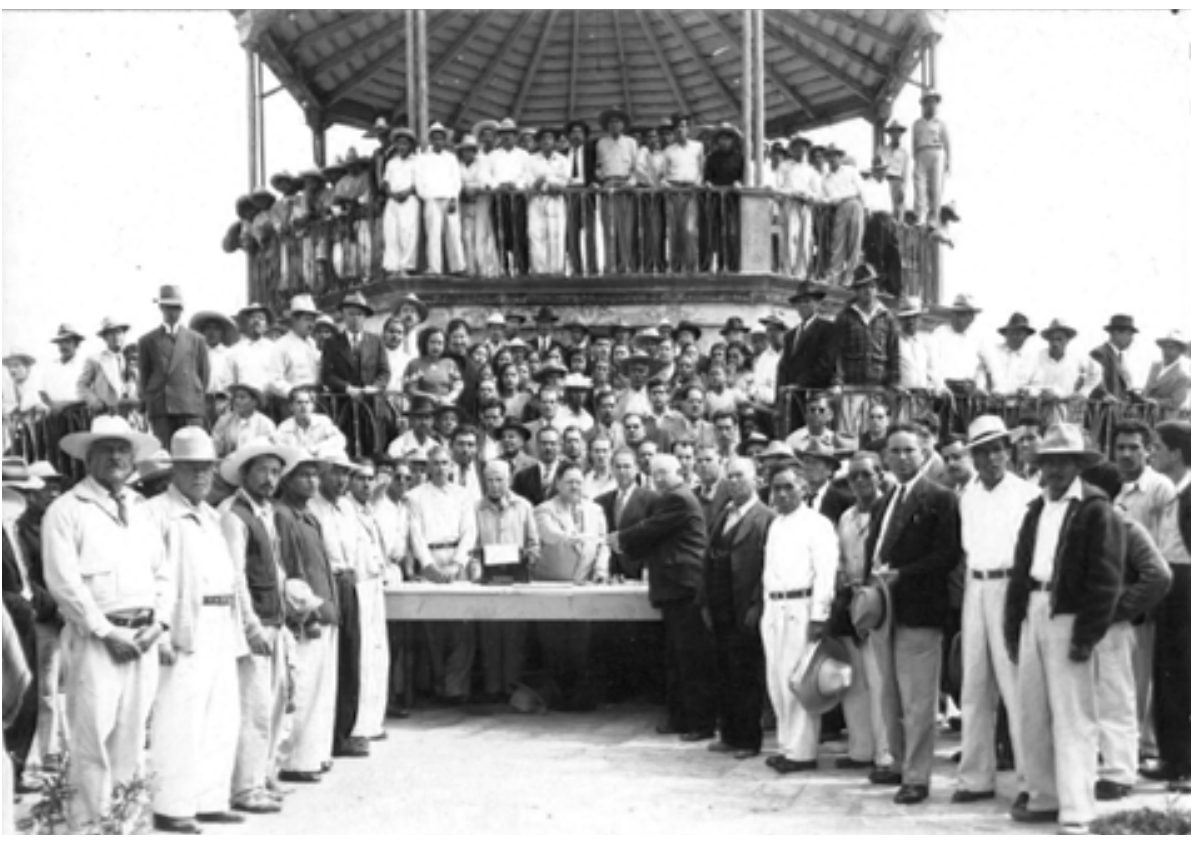




\section{e) Kiosco, 1940.}

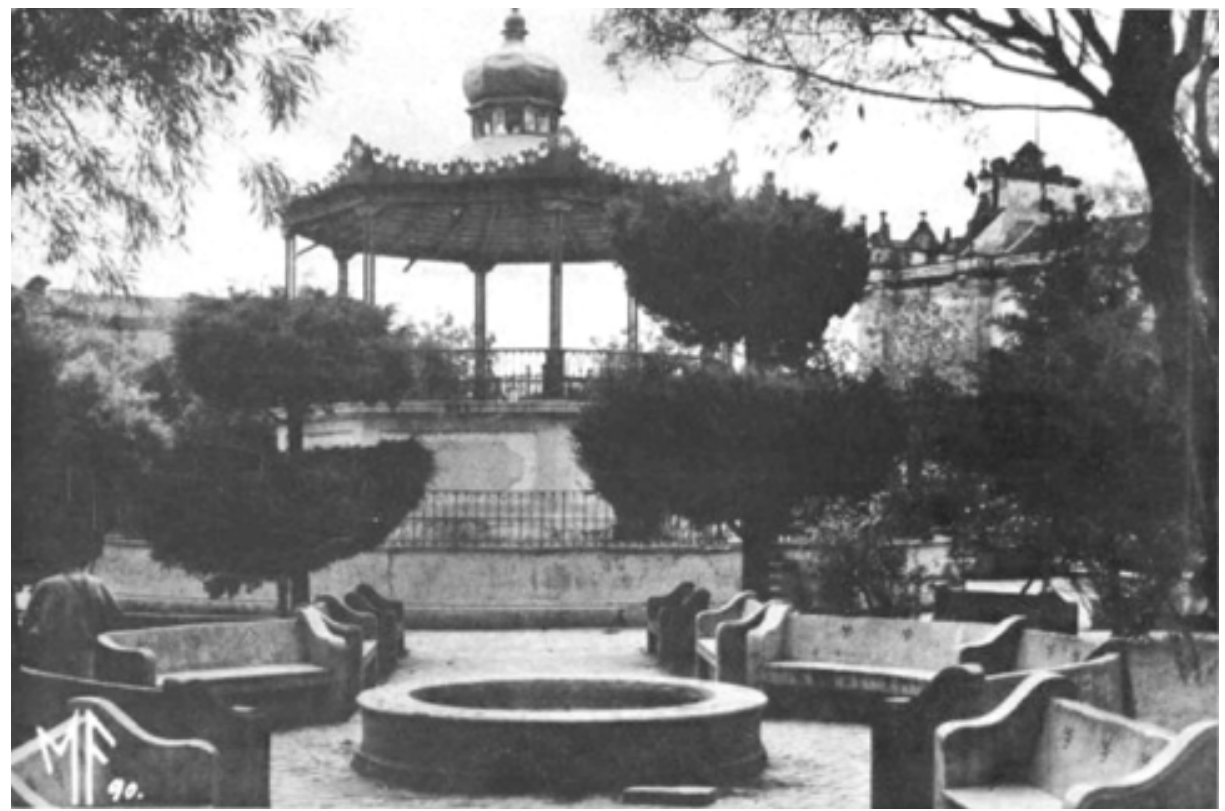

f) Parque, 1945.

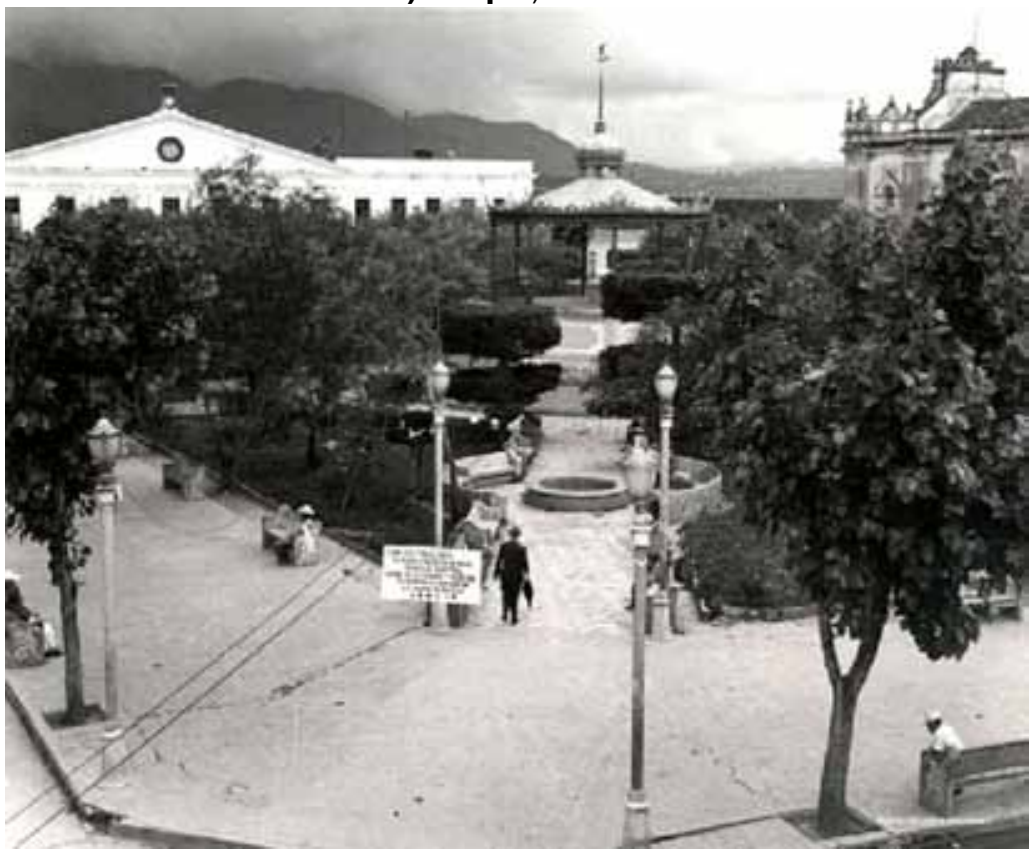

Revista LiminaR. Estudios sociales y humanísticos, año 8, vol. VIII, núm. 2, diciembre de 2010, San Cristóbal de Las Casas, Chiapas, México. ISSN: 1665-8027 
g) Plaza central, 1950.

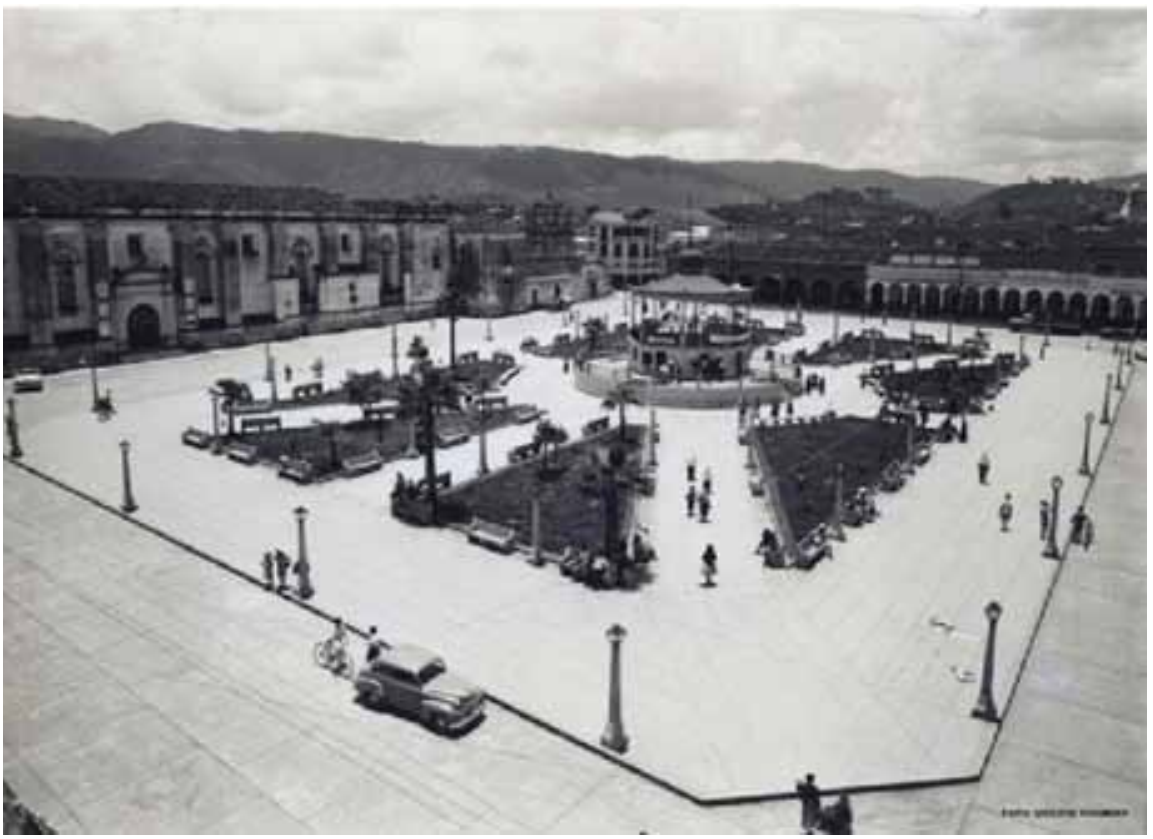

h) Kiosco, 1958.

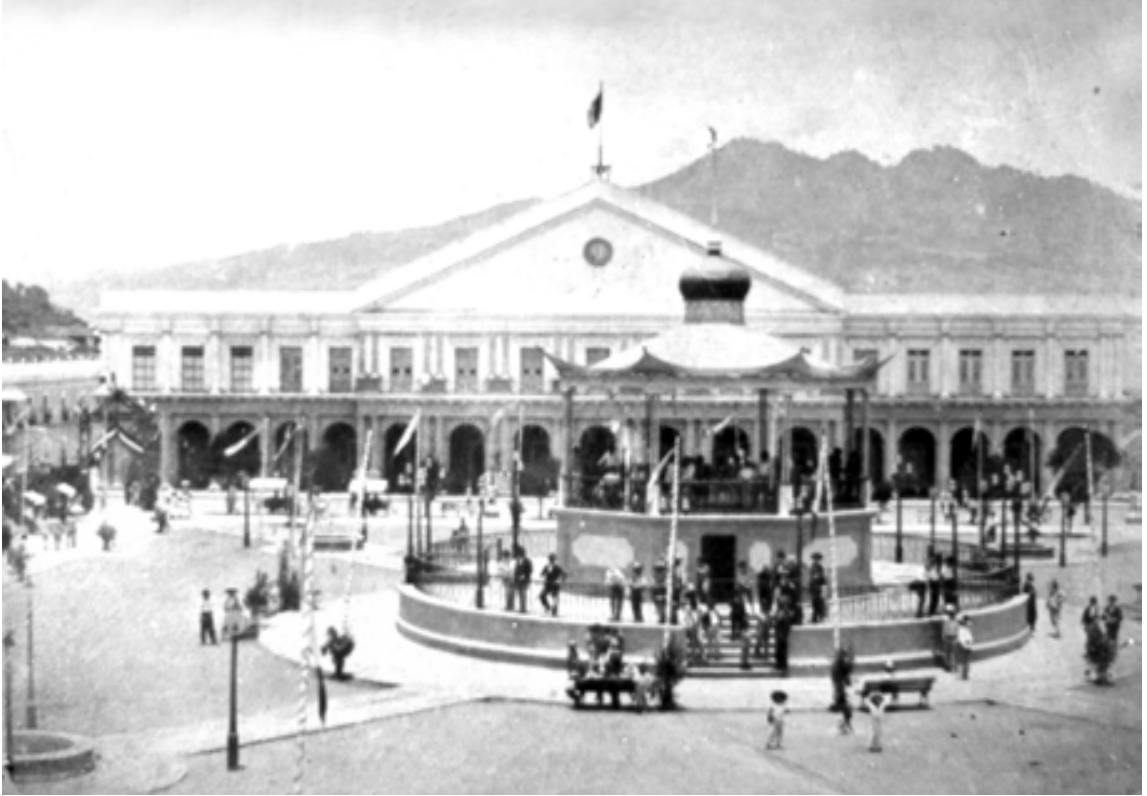


i) Parque, 1966.

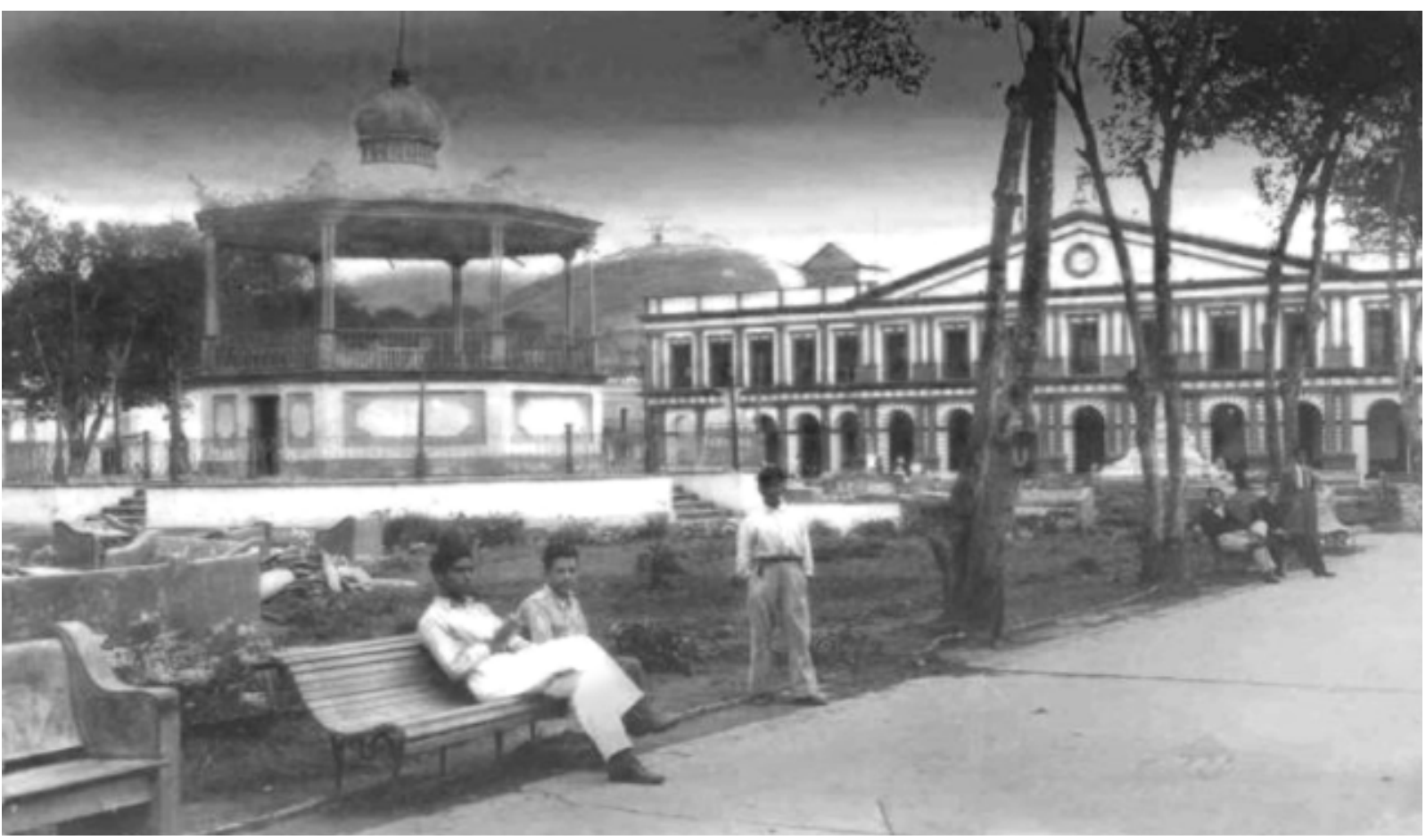

